\title{
PERANCANGAN SISTEM APLIKASI ARSIP DATA MENGGUNAKAN JAVA PADA KANTOR NOTARIS KABUPATEN BOGOR
}

\author{
Vena Grasheela Septiana ${ }^{1}$, Yuli Haryanto ${ }^{2}$, Adhityo Kuncoro ${ }^{3}$ \\ ${ }^{1,2,3}$ Universitas Indraprasta PGRI \\ Jalan Raya Tengah No.80, Kelurahan Gedong, Pasar Rebo, Jakarta Timur 13760, Jakarta \\ ${ }^{1}$ vgrasheela19@gmail.com, ${ }^{2}$ haryanto_yuli@yahoo.co.id ${ }^{3}$ adhityokuncoro@yahoo.com
}

\begin{abstract}
ABSTRAK
Aplikasi pengarsipan data klien berbasis java desktop merupakan sebuah aplikasi atau perangkat lunak komputer yang dirancang secara umum untuk mengolah data dan melakukan pengarsipan data-data klien. Masalah yang dihadapi di kantor notaris saat ini yaitu dalam melakukan pengarsipan data klien yang masih menggunakan cara manual, kesalahan proses pengarsipan dan proses pencarian data klien yang sudah lampau. Tujuan dibuatnya aplikasi arsip data yakni memudahkan dalam pengelolaan data klien dan memudahkan dalam pencarian data klien yang dibutuhkan. Metodologi yang digunakan dalam pembuatan aplikasi ini adalah metode waterfall, bahasa pemrograman yang digunakan adalah java, untuk tampilan menggunakan Netbeans, Database yang digunakan adalah MySQL, tools dan editor yang digunakan ialah XAMPP for windows 3.2.4, Netbeans IDE 8.2. Aplikasi ini akan digunakan sebagai media dalam pengarsipan data dan pengelolaan data klien. Hasil dari penelitian ini adalah sistem aplikasi arsip data menggunakan java pada kantor notaris Siti Maemunah SH,M.Kn. Kabupaten Bogor dimana aplikasi ini berfungsi sebagai aplikasi pengelolaan data, dan pengarsipan data klien.
\end{abstract}

Kata Kunci: Arsip Data, Aplikasi Java, Pengarsipan, Aplikasi Desktop

\begin{abstract}
Java desktop based client data archiving application is an application or computer software designed in general to process data and archive client data. The problems faced in the notary's office today are in archiving client data which still uses the manual method, errors in the archiving process and the process of searching for past client data. The purpose of making a data archive application is to make it easier to manage client data and make it easier to find the required client data. The methodology used in making this application is the waterfall method, the programming language used is java, for display using Netbeans, the database used is MySQL, the tools and editors used are XAMPP for windows 3.2.4, Netbeans IDE 8.2. This application will be used as a medium in data archiving and client data management. The result of this research is a data archive application system using java at the notary office of Siti Maemunah SH, M.Kn. Bogor Regency where this application functions as a data management application, and client data archiving.
\end{abstract}

Key Word: Data Archive, Java Applications, Archiving, Desktop Application

\section{PENDAHULUAN}

Perkembangan teknologi informasi di dunia semakin maju dan cepat, khususnya pada teknologi perangkat bergerak dan internet. Kebutuhan masyarakat didalam bidang teknologi ataupun IT sangat bermacammacam pengambilan informasi bisa dikatakan sangat mudah dikarenakan dapat mengakses secara cepat melalui perangkat bergerak dan web begitu juga dengan pengelolaan data yang sekarang sudah bisa menggunakan aplikasi desktop. Perkembangan ini juga mempengaruhi pengarsipan data dan dokumen. Menurut Sulistyo Basuki (2013:14)
“Arsip merupakan rekaman kegiatan atau peristiwa dalam berbagai bentuk dan media

sesuai dengan perkembangan teknologi informasi dan komunikasi yang dibuat dan diterima oleh Lembaga Negara, Pemerintah Daerah, Lembaga Pendidikan, Perusahaan, Organisasi Politik, Organisasi Masyarakat dan perorangan dalam pelaksanaan kehidupan bermasyarakat, berbangsa dan bernegara." Menurut Berto Nadeak (2016:54) mengemukakan bahwa "Perancangan merupakan langkah pertama dalam fase pengembangan rekayasa produk atau sistem" Menurut Rusdi Nur dkk (2018:5) menjelaskan 
bahwa "Perancangan merupakan kreasi untuk mendapatkan suatu hasil akhir dengan mengambil tindakan yang jelas" Sedangkan menurut Mulyadi (2016:5) mengemukakan bahwa "Sistem merupakan suatu jaringan prosedur yang dibuat menurut pola yang terpadu untuk melaksanakan kegiatan pokok perusahaan" dan Menurut Marimin dkk (2011:43) "Aplikasi merupakan program yang secara langsung dapat melakukan prosesproses yang digunakan dalam komputer oleh pengguna. Aplikasi merupakan kumpulan dari file-file tertentu yang berisi kode program yang menghubungkan antara pengguna dengan perangkat keras komputer."

Tujuan dalam penelitian ini adalah membuat sistem aplikasi arsip data pada Kantor Notaris Siti Maemunah SH.,M.Kn Kabupaten Bogor yang dapat melakukan pengelolaan arsip data sehingga pengarsipan di kantor lebih efektif dan efisien. Adapun Manfaat dari penelitian ini diantaranya (1) Kantor dapat menggunakan sistem aplikasi arsip data ini agar dapat mengefektifkan pengarsipan data klien. (2) Mempermudah pencarian arsip baik secara fisik maupun non fisik. Berdasarkan hasil pengamatan dan kajian teori yang telah disusun oleh penulis maka dapat dibangun kerangka berpikir tentang sistem aplikasi arsip data. (3) Sistem aplikasi arsip data klien berbasis desktop ini memudahkan pembuatan laporan setiap bulannya. (4) Dapat mengubah sistem manual ke sistem komputerisasi. Manfaat untuk lingkungan akademik, memberikan pengetahuan kepada mahasiswa untuk dijadikan referensi dalam pembuatan skripsi/ tugas akhir ataupun penulisan ilmiah yang berhubungan dengan Java Desktop, Sedangkan manfaat untuk peneliti sendiri adalah memberikan wawasan dan pengetahuan tentang teknik pengembangan sistem.

\section{METODE PENELITIAN}

Dalam melakukan penelitian diperlukan suatu metode penelitian yang sesuai dengan pokok permasalahan yang akan diteliti, Penelitian ini menggunakan penelitian kualitatif. Perangkat lunak yang akan dihasilkan adalah sistem aplikasi pengarsipan data, yaitu sebuah sistem yang dapat digunakan untuk menyimpan data klien, membuat laporan di Kantor Notaris Siti Maemunah SH.,M.Kn Kabupaten Bogor. Oleh karena itu untuk menghasilkan produk yang sesuai kebutuhan pengguna, maka dalam pengembangannya menggunakan model pengembangan perangkat lunak waterfall.

Menurut Sugiyono (2018:224) menjelaskan bahwa "Metode pengumpulan data diperoleh dari observasi, wawancara, dokumentasi, dan triangulasi." Dari pendapat diatas dapat disimpulkan bahwa instrumen penelitian merupakan alat bantu yang digunakan peneliti untuk mengumpulkan informasi tentang data yang sedang diteliti. Metode Pengumpulan Data yang peneliti lakukan diantaranya: Observasi dilakukan dengan melakukan pengamatan di Kantor Notaris Siti Maemunah SH.,M.Kn Kabupaten Bogor, hal yang diamati dalam observasi ini yaitu proses pembuatan surat, pembuatan laporan dan pengarsipan data klien serta tugas dari masing-masing pegawai yang bekerja di kantor tersebut.

Wawancara dalam penelitian ini wawancara dilakukan untuk proses pengumpulan data yang diperlukan untuk mengembangkan sistem aplikasi arsip data. Wawancara dilakukan dengan pimpinan kantor yaitu notaris, dengan ibu Siti Maemunah SH.,M.Kn dan hasil wawancara yang telah dilakukan adalah Kantor Notaris Siti Maemunah SH, M.Kn Kabupaten Bogor juga bergerak dibidang PPAT, dimana kantor notaris ini dapat melaksanakan sebagian kegiatan pendaftaran tanah dan membuat akta sebagai bukti telah dilakukannya perbuatan hukum mengenai hak atas tanah atau hak milik atas satuan rumah dan juga menandatangani akta jual beli, dan sistem pengarsipan data klien menggunakan buku khusus arsip Dokumentasi, dalam penelitian ini dokumen sebagai pendukung dan pelengkap mengenai hasil observasi dan wawancara pada Kantor Notaris Siti Maemunah SH,M.Kn Kabupaten Bogor

Studi Kepustakaan, pengumpulan data dan informasi yang penulis lakukan adalah dengan datang ke toko buku, membaca beberapa buku, dan browsing di internet yang memuat uraian sistematis tentang kajian literatur dan hasil 
penelitian sebelumnya yang berhubungan dengan penelitian yang dilakukan. Peneliti melakukan studi kepustakaan baik sebelum maupun selama melakukan penelitian.

\section{HASIL DAN PEMBAHASAN}

Pada sistem aplikasi arsip data yang akan dibuat peneliti menganggap akan memudahkan dalam pengelolaan data, dan pengarsipan data klien sehingga pencarian data klien lebih mudah dan cepat.

Diagram Konteks Sistem Yang Diusulkan Diagram Konteks Sistem yang Diusulkan pada Kantor Notaris Siti Maemunah SH,M.Kn Kabupaten Bogor. Diagram konteks menampilkan keseluruhan sistem serta menggambarkan dengan jelas

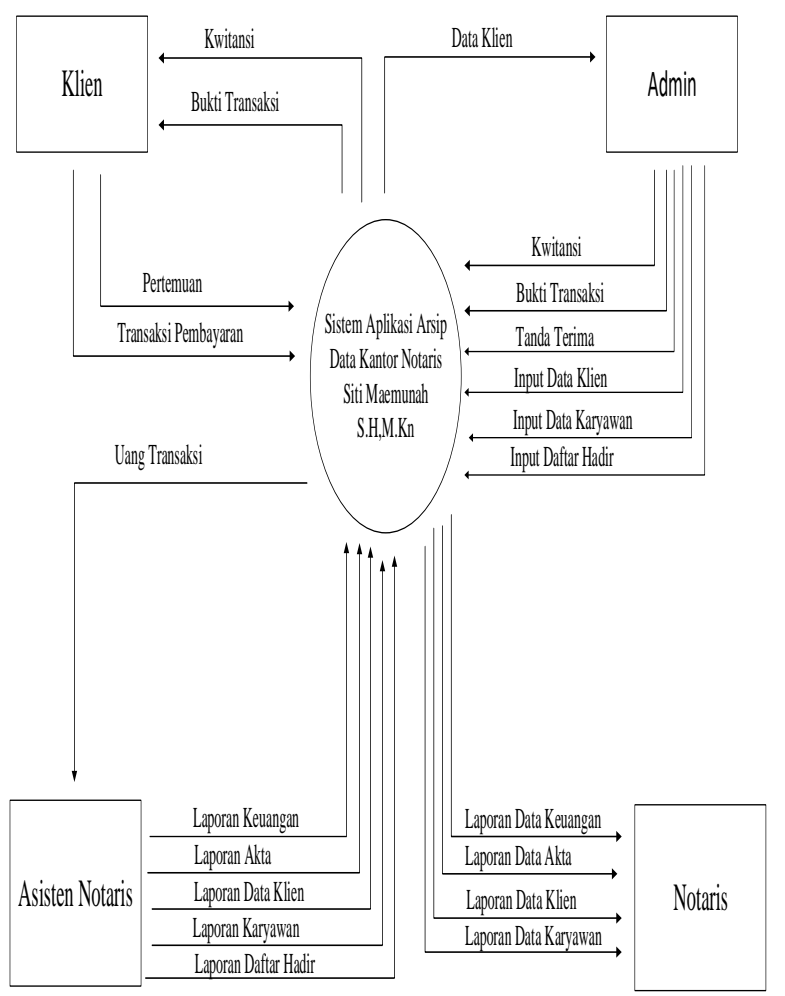

Gambar 1. Diagram Konteks Sistem yang Diusulkan

\section{Diagram Nol Sistem yang Diusulkan}

Diagram nol sistem yang diusulkan ini menampilkan tentang penjabaran sistem yang secara jelas dan detail.

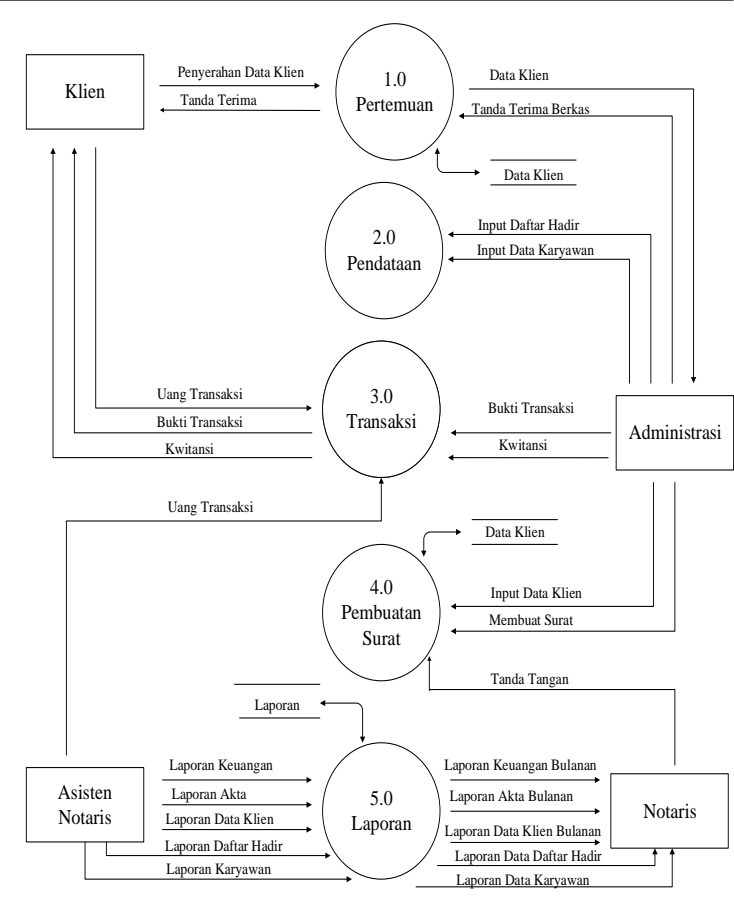

Gambar 2. Diagram Nol Sistem yang Diusulkan

\section{Entity Relationship Diagram}

pada entity relationship diagram menjelaskan susunan antar data yang disimpan ke dalam sistem dengan menggunakan notasi dan simbol

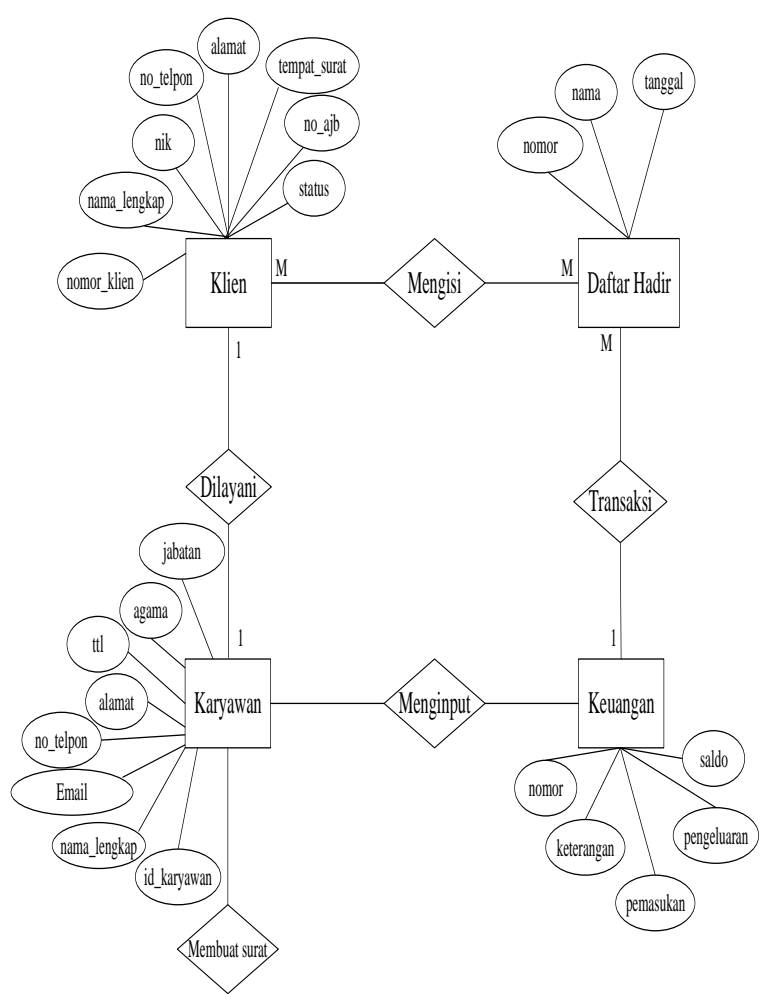

Gambar 3. Entity Relationship Diagram 


\section{Normalisasi Tahap Pertama (1NF)}

Normalisasi tahap pertama merupakan tahapan awal menormalisasikan table

\begin{tabular}{|c|}
\hline * nomor \\
nama \\
tanggal \\
nomor \\
nama_lenglcap \\
*nik \\
no_telpon \\
alamat \\
posisi_surat \\
no_ajb \\
gtatus \\
id_karyawan \\
nama_lenglcap \\
email \\
no_telpon \\
alamat \\
ttl \\
agama \\
jabatan \\
no_telpon \\
nomor \\
keterangan \\
pemasukan \\
pengeluaran \\
saldo \\
\end{tabular}

Gambar 4. Normalisasi Tahap Pertama (1NF)

\section{Normalisasi Tahap Kedua (2NF)}

Normalisasi tahap kedua menampilkan tabel yang sudah didekomposisikan menjadi beberapa tabel dan memiliki primary key dan atribut kunci yang unik.

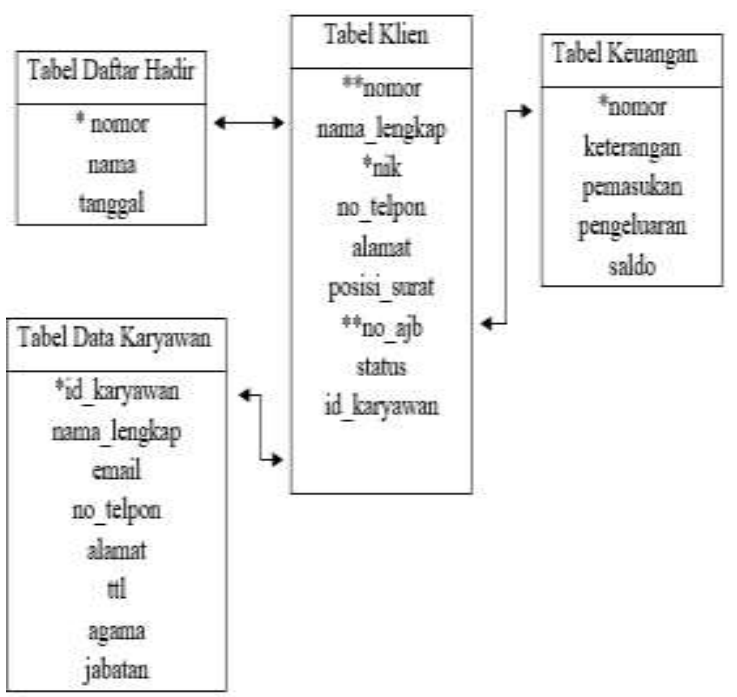

Gambar 5. Normalisasi Tahap Kedua (2NF)

\section{Tampilan Login}

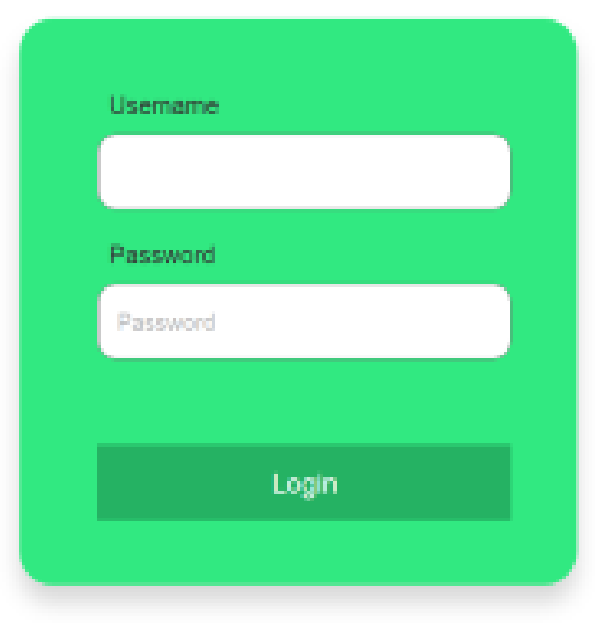

Gambar 6. Tampilan Login

Tampilan form masukan login muncul pada awal program dijalankan. Pengguna dihadapkan pada kotak dialog untuk memasukan username dan password. Jika user dan password sesuai, maka tampilan akan masuk ke menu utama.

\section{Tampilan Menu Utama}
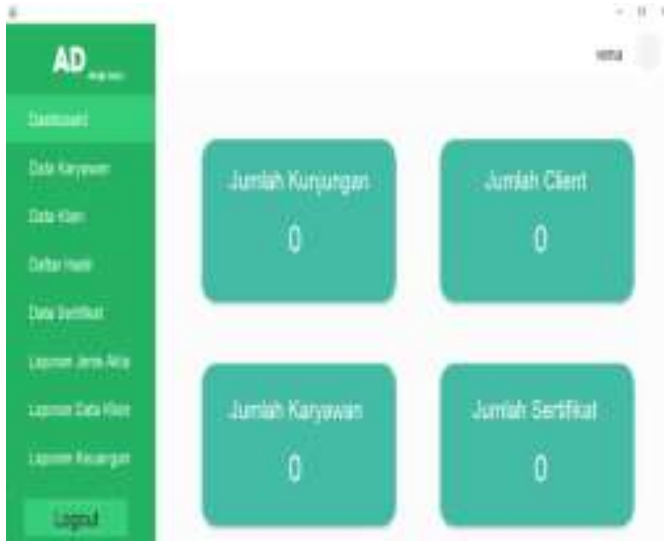

Gambar 7. Tampilan Menu Utama

Tampilan form menu utama terdapat beberapa sub menu diantaranya menu data karyawan, data klien, daftar hadir, data sertifikat, dan sub menu laporan. Sub menu digunakan untuk menginput data dan menyimpan ke database. Jika pengguna memilih logout maka akan keluar dari menu utama dan akan kembali ke menu login. 


\section{Tampilan Form Data Karyawan}

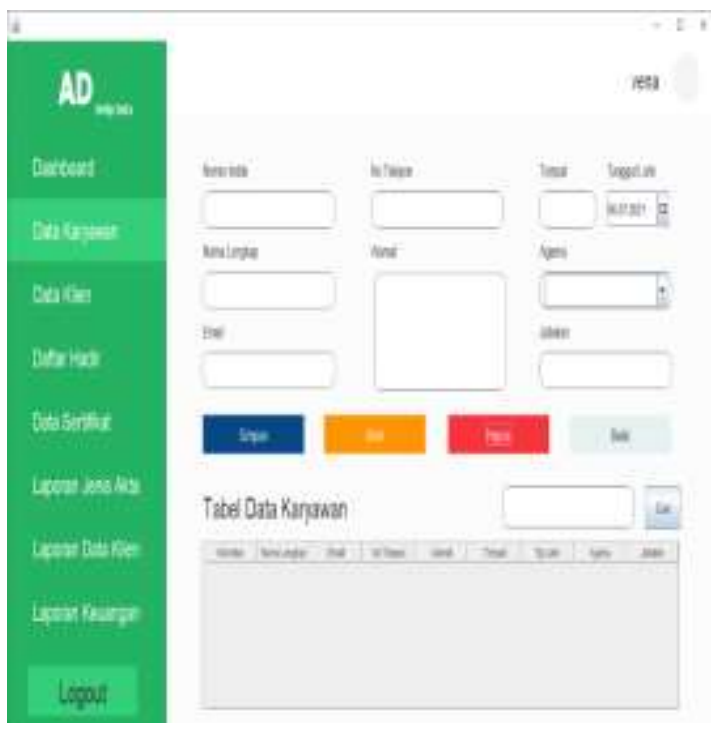

Gambar 8. Tampilan Form Data Karyawan

Pada tampilan form menu data karyawan terdapat informasi data karyawan data yang diinput akan tersimpan ke dalam table dan disimpan di database.

\section{Tampilan Form Data Klien}

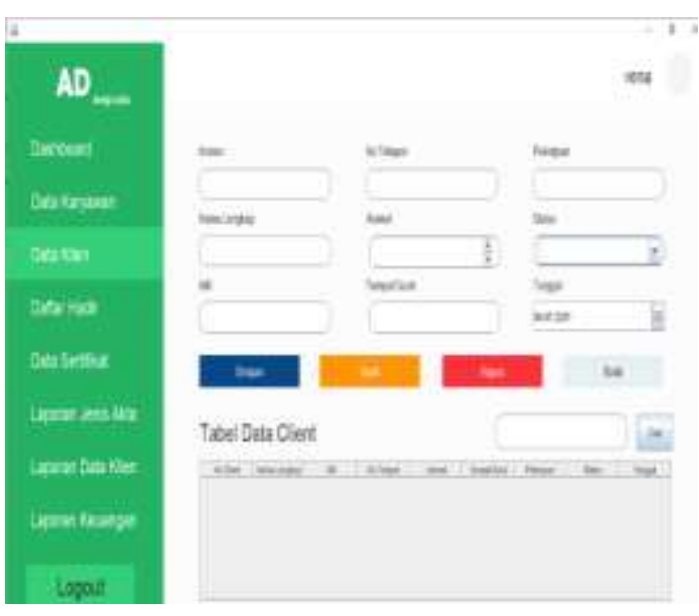

Gambar 9. Tampilan Form Data Klien

Pada tampilan form data klien terdapat informasi data klien dan berfungsi sebagai tampilan untuk mengubah, menginput, dan menyimpan data klien serta cetak laporan. Data yang diinput akan tersimpan dalam database.
Tampilan Form Daftar Hadir

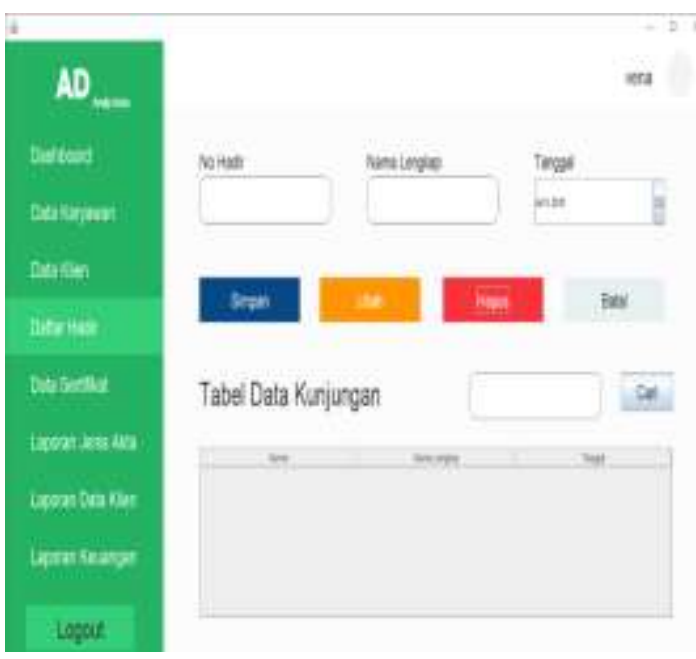

Gambar 10. Tampilan Form Daftar Hadir

Tampilan daftar hadir ini berfungsi sebagai tampilan untuk menambahkan daftar hadir klien sebelum melakukan transaksi tampilan ini dapat dicetak sebagai untuk dilakukan penandatanganan oleh klien

\section{Tampilan Form Laporan Jumlah Akta}

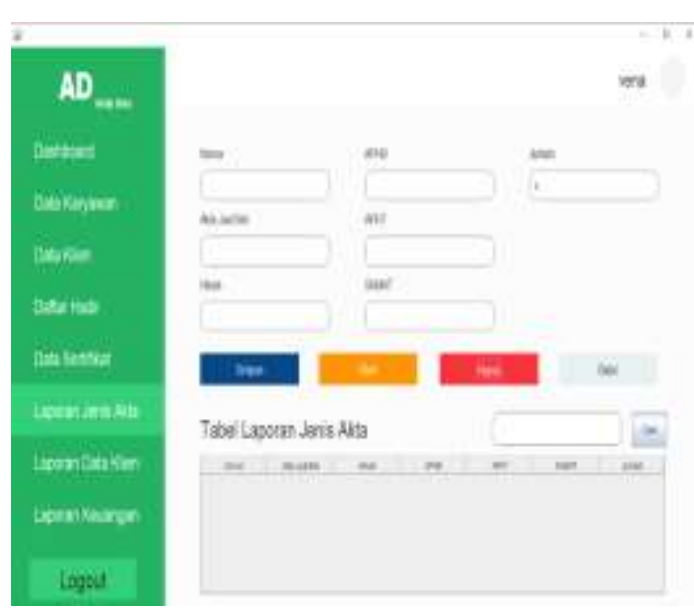

Gambar 11. Tampilan Form Laporan Jumlah Akta

pada tampilan form laporan jumlah akta, pengguna dapat melihat jumlah dari setiap jenis akta yang masuk setiap bulannya. Pilih cetak laporan untuk mencetak laporan jumlah akta. 


\section{Tampilan Form Laporan Data Klien}
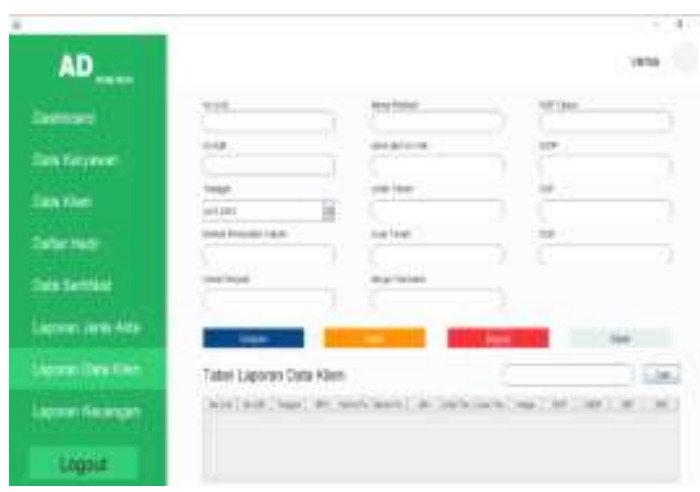

Gambar 12. Tampilan Form Laporan Data Klien

pada tampilan form laporan data klien pengguna dapat melihat semua data klien dengan lengkap yang diambil dari inputan data klien, dan kelengkapan yang dibawa klien saat proses pembuatan surat, pilih cetak laporan untuk mencetak laporan data klien setiap bulan

\section{Tampilan Form Data Keuangan}

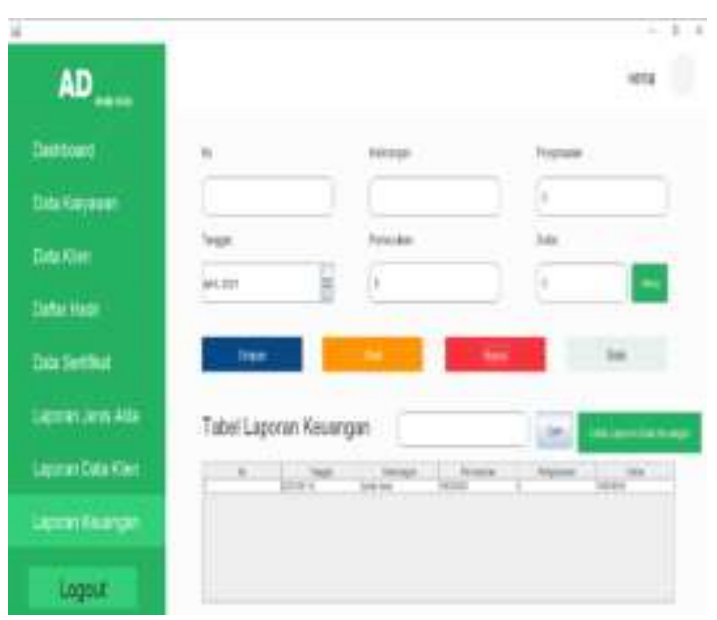

Gambar 13. Tampilan Form Data Keuangan

pada tampilan form data keuangan, terdapat data keuangan kantor setiap bulannya seperti pemasukan, pengeluaran dan saldo kantor. Pilih cetak laporan untuk mencetak laporan data keuangan setiap bulannya.
Tampilan Laporan Data Karyawan

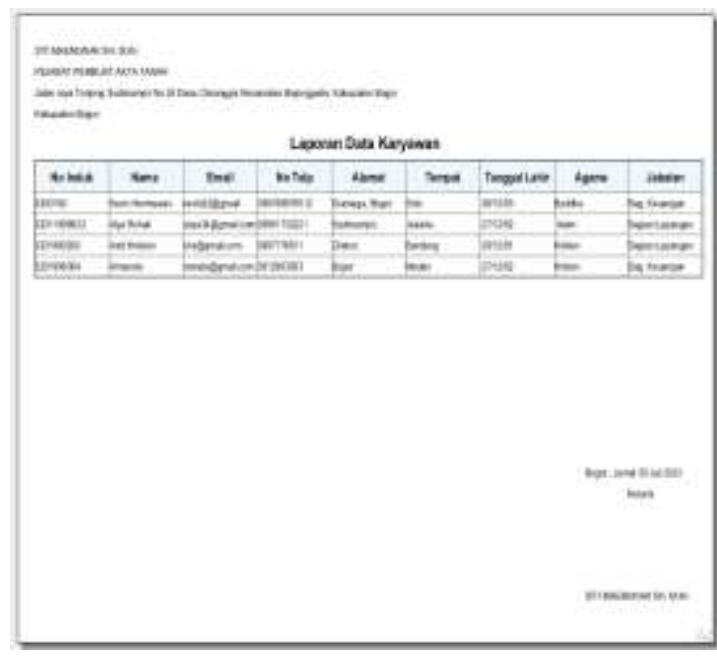

Gambar 14. Tampilan Laporan Data Karyawan

Laporan Data karyawan dibuat untuk mengetahui data karyawan yang bekerja pada kantor notaris Siti Maemunah SH,M.Kn Kabupaten Bogor. Laporan data karyawan ini terdiri dari NIK, Nama, Email, Nomor telepon, Alamat, Tempat tanggal lahir, dan posisi karyawan

\section{Tampilan Laporan Data Klien}

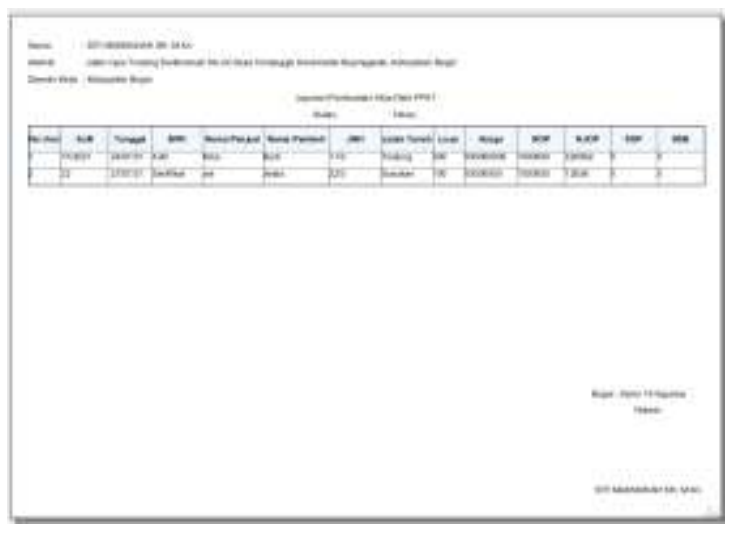

Gambar 15. Tampilan Laporan Data Klien

Laporan data klien ini untuk mengetahui data setiap klien yang membuat surat di kantor notaris dan akan dilaporkan kepada pimpinan atau notaris setiap bulannya. Laporan data klien ini berisi diantaranya Nomor AJB, Nama Penjual, Nama Pembeli, Tanggal, Bentuk Perbuatan Hukum dan yang lainnya. 


\section{Tampilan Laporan Keuangan}

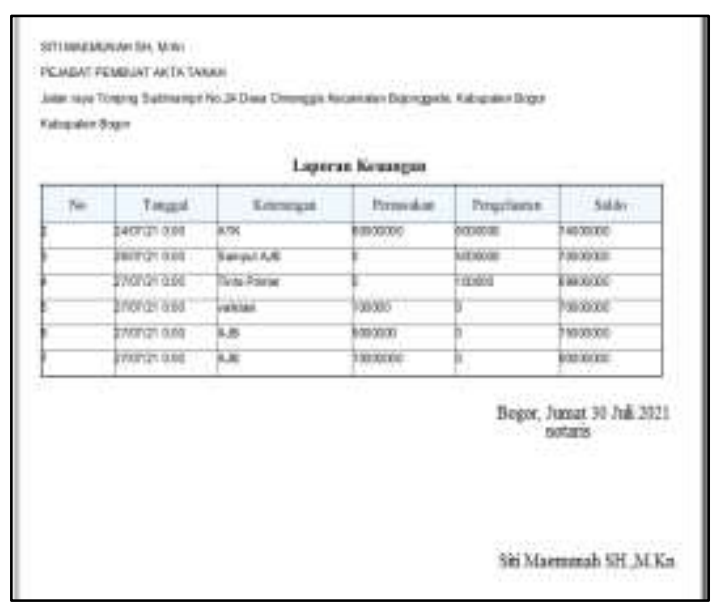

Gambar 16. Tampilan Laporan Keuangan

Laporan Keuangan dibuat untuk mengetahui saldo, data keuangan yang masuk dan yang keluar pada kantor notaris Siti Maemunah SH,M.Kn Kabupaten Bogor. Dan akan dilaporkan setiap bulannya kepada pimpinan kantor.

\section{SIMPULAN DAN SARAN}

Penelitian yang dilakukan adalah dengan menggunakan metode penelitian kualitatif, grounded theory, metode pengumpulan data dalam penelitian ini menggunakan cara observasi, wawancara, dan dokumentasi tujuan dari penelitian ini adalah membuat sistem aplikasi arsip data yang lebih efektif dan efisien, membuat pencarian data lebih cepat sehingga tidak memakan waktu yang cukup lama. Tahap pengembangan sistem pada aplikasi yang peneliti buat menggunakan metode waterfall. Dan aplikasi yang dibuat menggunakan bahasa pemrograman yaitu Java dengan editor Netbeans IDE 8.2 sistem yang dibangun lebih terstruktu dan mudah untuk digunakan, penyimpanan data lebih terpusat dan tidak terpisah karena disimpan pada database yang sama.

Terdapat beberapa faktor penghambat dalam pembuatan aplikasi ini, yaitu kualitas sumber daya manusia dalam pengoperasian komputer dan diperlukan penyesuaian dari karyawan yang bekerja, selain faktor penghambat peneliti juga menemukan faktor pendukung seperti kesediaan waktu, ketersediaan sistem dan alat yang menjadi pendukung contohnya seperti laptop. Berdasarkan penelitian yang peneliti lakukan, dapat disimpulkan bahwa : Aplikasi yang peneliti buat dapat memudahkan bagian administrasi dalam menjalankan sistem pengarsipan pada Kantor Notaris Siti Maemunah SH, M.Kn Kabupaten Bogor, dengan adanya aplikasi ini data-data di kantor lebih aman dan terstruktur baik arsip fisik maupun arsip non fisik yang disimpan di database yang sama. Pencarian data akan lebih cepat karena peneliti membuat fitur informasi lokasi arsip yang berbentuk fisik, sehingga memudahkan karyawan dalam pencarian arsip fisik, lebih cepat dan rapih.

Berdasarkan kesimpulan diatas, maka saran untuk pengembangan sistem aplikasi di masa mendatang baik dalam desain dapat dikembangkan dan aplikasi ini hendaknya bisa dikembangkan menjadi aplikasi mobile ataupun web yang lebih fleksibel dan penambahan fasilitas-fasilitas ataupun fitur yang lebih banyak, sehingga pengarsipan data klien semakin efisien.

\section{DAFTAR PUSTAKA}

Berto Nadeak, A. P. (2016). Perancangan Aplikasi Pembelajaran Internet Dengan Menggunakan Metode Computer Based Instruction. Jurnal Riset Komputer (JURIKOM), Vol. 3 No. 4:54 PERANCANGAN .

Marimin, M. P. (2011). Sistem Informasi Manajemen Sumber Daya Manusia. Jakarta: Grasindo.

Mulyadi. (2016). Sistem Informasi Akuntansi. Jakarta: Salemba Empat.

Nur, R. \&. (2018). Perancangan Mesin-Mesin Industri. Yogyakarta: Deepublish. .

Sugiyono, P. D. (2018). Metode Penelitian Kuantitatif, Kualitatif, dan $R \& D$. Bandung: Alfabeta.

Basuki, S. (2013). Adminsitrasi Arsip. Jakarta: Sagung Seto. 